\title{
OR-65
}

\section{Potential of Pterostilbene in Cancer Chemoprevention by Enhancing Phase 2 Detoxifying Enzymes}

\author{
Zaliha Harun and Ahmad Rohi Ghazali* \\ Biomedical Science Programme, School of Diagnostic and Applied Health Sciences, Faculty of Health Sciences, \\ Universiti Kebangsaan Malaysia, Jalan Raja Muda Abdul Aziz, 50300 Kuala Lumpur, Malaysia; \\ E-mail:rohi@fskb.ukm.my
}

Detoxifiying enzymes are one of the potential tools in protection against xenobiotics which may lead to cancer. Induction of phase 2 detoxifying enzymes such as glutathione S-transferase (GST) and its thiol conjugate, glutathione (GSH) as well as the $\mathrm{NAD}(\mathrm{P}) \mathrm{H}$ : quinoneoxidoreductase (NQO1) facilitate the excretion of carcinogens thus protect from carcinogenesis. Pterostilbene, an analogue of resveratrol, has demonstrated numerous pharmacological activities including chemoprevention. This study was conducted to investigate the potential of pterostilbene as a cancer chemopreventive agent using HT-29 colon cancer cell line to study the modulation of GST and NQO1 activities as well as the GSH level. Initially, our group established the optimum dose of 24 hours pterostilbene treatment on HT-29 cell line using MTT assay. Then, the effects of pterostilbene (0-50 $\mu \mathrm{M})$ towards GST and NQO1 activity and GSH level were determined using GST, NQO1 and Ellman assays respectively. Protein expressions of the enzymes were further establised using Western Blotting techniques. MTT assay of pterostilbene $(0-100 \mu \mathrm{M})$ showed that pterostilbene did not cause cytotoxicity on HT-29 cell line. Treatment of pterostilbene increased GST activity in the cell line significantly $(\mathrm{p}<0.05)$ at 12.5 and $25.0 \mu \mathrm{M}$ that were reported as $4277.22 \pm 489.32$ and $4617.12 \pm 345.95 \mathrm{nmol} / \mathrm{min} / \mathrm{mg}$ protein respectively. In addition, treatment of $50 \mu \mathrm{M}$ pterostilbene increased the GSH level significantly $(\mathrm{p}<0.05)$ with the value of $75.54 \pm 5.92 \mathrm{nmol} / \mathrm{mg}$ protein. Pterostilbene also enhance NQO1 activity significantly $(\mathrm{p}<0.05)$ at $12.5 \mu \mathrm{M}$ and $50 \mu \mathrm{M}$ with the value of $3973.82 \pm 177.33$ and $4219.60 \pm 321.18 \mathrm{nmol} / \mathrm{min} / \mathrm{mg}$ protein respectively. Hence, pterostilbene is a potential chemopreventive agent through its modulation of detoxifiying enzymes.

Keywords: Pterostilbene, detoxifiying enzymes, glutathione S-transferase, glutathione, NAD(P)H: quinoneoxidoreductase. 